Article

\title{
Lipid Species in the GI Tract are Increased by the Commensal Fungus Candida albicans and Decrease the Virulence of Clostridioides difficile
}

\author{
Jesus A. Romo ${ }^{1, * \mathbb{D}}$, Laura Markey ${ }^{2}$ and Carol A. Kumamoto ${ }^{1, *}$ \\ 1 Department of Molecular Biology and Microbiology, Tufts University, Boston, MA 02111, USA \\ 2 Graduate Program in Molecular Microbiology, Graduate School of Biomedical Sciences and Department of \\ Molecular Biology and Microbiology, Tufts University, Boston, MA 02111, USA; Laura.markey@tufts.edu \\ * Correspondence: Jesus.romo@tufts.edu (J.A.R.); carol.kumamoto@tufts.edu (C.A.K.)
}

Received: 13 May 2020; Accepted: 30 June 2020; Published: 3 July 2020

check for updates

\begin{abstract}
Prior antibiotic treatment is a risk factor for Clostridioides difficile infection (CDI); the commensal gut microbiota plays a key role in determining host susceptibility to the disease. Previous studies demonstrate that the pre-colonization of mice with a commensal fungus, Candida albicans, protects against a lethal challenge with $C$. difficile spores. The results reported here demonstrate that the cecum contents of antibiotic-treated mice with $C$. albicans colonization contained different levels of several lipid species, including non-esterified, unsaturated long-chain fatty acids compared to non-C. albicans-colonized mice. Mice fed olive oil for one week and challenged with $C$. difficile spores showed enhanced survival compared to PBS-fed mice. The amount of olive oil administered was not sufficient to cause weight gain or to result in significant changes to the bacterial microbiota, in contrast to the effects of a high-fat diet. Furthermore, the direct exposure of $C$. difficile bacteria in laboratory culture to the unsaturated fatty acid oleic acid, the major fatty acid found in olive oil, reduced the transcription of genes encoding the toxins and reduced the survival of bacteria in the post-exponential phase. Therefore, the effects of $C$. albicans on the metabolite milieu contributed to the attenuation of $C$. difficile virulence.
\end{abstract}

Keywords: Candida albicans; Clostridioides difficile; colonization; susceptibility; non-esterified fatty acids

\section{Introduction}

The opportunistic pathogenic fungus Candida albicans is the most common fungal colonizer of the human gastrointestinal tract [1-4]. C. albicans has been shown to affect the host immune system [5-9], and interact with the gut microbiome and pathogenic microorganisms [10-15]. Moreover, C. albicans has been shown to have significant effects on bacterial population diversity after antibiotic treatment in a murine model [16], suggesting a significant role as a commensal. Currently, there is a lack of knowledge about the role fungi play during the bacterial infection of the gastrointestinal tract.

Clostridioides difficile is an anaerobic, Gram-positive, spore-forming, and toxin-producing bacterial pathogen able to cause mild (antibiotic-associated diarrhea) $[17,18]$ to severe, potentially fatal, gastrointestinal disease (pseudomembranous colitis, toxic megacolon) [19-22] primarily in those who are elderly, have been hospitalized, and/or received a course of broad-spectrum antibiotics [23,24]. Antibiotic treatment and Clostridioides difficile infection (CDI) are inextricably linked and therefore the disease has been labeled as an urgent public health concern by the United States White House's National Action Plan for Combating Antibiotic-resistant Bacteria (CDC.gov) due to its high morbidity, the medical costs it creates [25-27], and the treatment difficulty (i.e., the emergence of drug resistance to fluoroquinolones and disease relapse) [20,28-36]. 
C. difficile spores are acquired via the fecal-oral route and germinate in the intestinal tract. Antibiotic treatment leads to the disruption and decrease in diversity of the protective host gastrointestinal microbiota, allowing $C$. difficile to flourish, colonize the lower gastrointestinal tract, secrete toxins, and cause epithelial damage [37]. C. difficile infection (CDI) is a complex disease whose pathology is primarily caused by the secretion of the toxins TcdA and TcdB. Both toxins are monoglycosyltransferases that target Rho family GTPases leading to cell cytoskeleton disruption and cell death [38].

Host susceptibility and CDI severity is influenced by the host bile acid metabolome. Host-derived primary bile acids such as cholate (CA), deoxycholate (DCA), and taurocholate (TCA) are able to stimulate $C$. difficile spore germination $[39,40]$. Once these primary bile acids enter the small and large intestines, they can be converted into a variety of chemically diverse species of secondary bile acids by the resident microbiota [41]. Secondary bile acids inhibit $C$. difficile spore germination and are therefore crucial for protectiveness [23,39,42-44]. Buffie and co-workers identified key bacterial taxa required for $C$. difficile colonization resistance [43]. Among these, Clostridium scindens was highly associated with CDI resistance. Furthermore, the removal of $C$. scindens from the murine gastrointestinal tract by antibiotic treatment led to a reduction in secondary bile acids and increased sensitivity to CDI, while the administration of $C$. scindens restored secondary bile acid pools and CDI resistance. Thus, the alteration of microbiota composition and the associated changes in the bile acid metabolome accompanied changes in susceptibility to CDI. These studies highlight the role of the host microbiota in creating a metabolic environment that is unfavorable to $C$. difficile. Additionally, the host diet is able to influence CDI susceptibility. Recently, Hryckowian and co-workers demonstrated that the supplementation of microbiota accessible carbohydrates (MACs) into the diet of antibiotic-treated mice reduced C. difficile burdens while murine diets deficient in MACs perpetuate CDI [45]. Moreover, MACs diet selected specific microbial taxa whose metabolic end products consist of high levels of short-chain fatty acids (SCFA) such as acetate, propionate, and butyrate, which are known to have antagonistic effects on $C$. difficile. This study showed an association between the host diet, levels of SCFA, and the $C$. difficile burden. Interestingly, this reduction in virulence was independent of the toxin production as the authors identified high levels of toxin.

The role of host bacterial microbiota during CDI and in preventing CDI has been well characterized, but a role for fungal gastrointestinal colonizers has not been well studied and is therefore largely unknown. Previous clinical observations have yielded contradicting reports suggesting that the fungus C. albicans appears to have a protective $[46,47]$ effect or play a negative $[48,49]$ role by exacerbating CDI or reducing the effectiveness of FMT [50]. Our group recently utilized a murine model of the C. albicans gastrointestinal colonization followed by CDI in order to investigate the role of fungi [51]. In these experiments, antibiotic-treated mice were pre-colonized with C. albicans for prolonged periods of time (3 weeks). Long-term colonization allowed the host gastrointestinal microbiota to begin to recover from the antibiotic treatment in the presence of $C$. albicans. Mice were then administered clindamycin and challenged with a highly virulent $C$. difficile strain (UK1) [44]. Mice pre-colonized with C. albicans displayed increased survival showing that the $C$. albicans pre-colonization was protective in this model.

In this study, we further characterized the ecological effects of C. albicans that contribute to the protective effects we observed previously [51]. We hypothesized that C. albicans modifies the metabolite milieu of the gastrointestinal tract environment, which could influence the ability of C. difficile to cause disease. We performed an untargeted metabolomics analysis of cecum contents of antibiotic-treated mice with or without $C$. albicans colonization and found that $C$. albicans pre-colonized mice had increased levels of non-esterified fatty acids (NEFA), particularly unsaturated fatty acids. To mimic this increase in fatty acids, mice were fed olive oil, an oil rich in triglycerides containing an unsaturated fatty acid, oleic acid. These mice displayed an increased survival rate when challenged with CDI. Moreover, the oleic acid supplementation of $C$. difficile cultures led to a reduction in the transcription of genes encoding $C$. difficile toxins. These findings are consistent with the model in which the environmental modification of the host gastrointestinal tract by C. albicans includes increasing levels of unsaturated fatty acids, which play a role in the overall reduction of the virulence of $C$. difficile. 


\section{Materials and Methods}

\subsection{Strains and Growth Conditions}

C. albicans strain CKY101, [52] a virulent strain derived from the sequenced strain SC5314, was used for all studies. Cells were prepared for mouse inoculation by growth at $37^{\circ} \mathrm{C}$ in YPD broth ( $1 \%$ yeast extract (BD, Sparks, MD, USA cat. 212750), 2\% peptone (Difco, Detroit, MI, USA cat. 0118-17-0), and 2\% glucose (Sigma-Aldrich, St. Louis, MO, USA cat. G8270)) [53] for 21-24 hrs.

C. difficile strain UK1, a NAP1/027/BI human epidemic strain [44], was used for all studies. Cultures were grown in pre-reduced TY broth ( $3 \%$ tryptose, $2 \%$ yeast extract, $0.1 \%$ thioglycolate, $\mathrm{pH} 7.4$ ) [54]. Spores were isolated as previously described [39] except that the gradient purification was omitted. For the enumeration of $C$. difficile vegetative cells and spores in the extracts from mice, the samples were plated on pre-reduced TCCFA plates (Taurocholate (Calbiochem, San Diego, CA, USA cat. 580217), cycloserine (Sigma-Aldrich, St. Louis, MO, USA cat. C6880), cefoxitin (Sigma-Aldrich, St. Louis, MO, USA cat. C4786), fructose (Macron Fine Chemicals, Center Valley, PA, USA cat. 7756-12)) [40] and incubated at $37^{\circ} \mathrm{C}$ for 2 days in an anaerobic chamber. Spores were enumerated by heating the samples at $60^{\circ} \mathrm{C}$ for $10 \mathrm{~min}$, followed by plating on pre-reduced TCCFA plates.

\subsection{GI Colonization in Mice}

All the experiments using animals were done in compliance with the NIH Guide for the Care and Use of Laboratory Animals and Tufts University IACUC guidelines. Animal experimentation was approved by the Tufts Institutional Animal Care \& Use Committee, 10/08/2018, protocol number B2018-84.

Five-week-old female C57BL/6 mice (Jackson Laboratory, Bar Harbor, ME, USA) were co-housed in a large cage $\left(24^{\prime \prime} \times 17^{\prime \prime}\right)$ for a week, and then treated with the antibiotic cefoperazone (Sigma-Aldrich, St. Louis, MO, USA cat. C4292, $0.5 \mathrm{gm} / \mathrm{L}$ ) in drinking water for 10 days while in the large cage. All the mice were tested at the end of cefoperazone treatment and shown to be negative for cultivable fungi on YPD-SA agar medium (YPD agar plus $100 \mu \mathrm{g} / \mathrm{mL}$ streptomycin (Sigma-Aldrich, St. Louis, MO, USA cat. S6501) and $50 \mu \mathrm{g} / \mathrm{mL}$ ampicillin (Sigma-Aldrich, St. Louis, MO, USA cat. A9518)) incubated for 2 days at $37^{\circ} \mathrm{C}$. On the 10th day of antibiotic exposure, some mice were inoculated orally with $5 \times 10^{7}$ C. albicans cells in $25 \mu \mathrm{L}$.

All mice were transferred from the large cage to standard sized cages, housing 4 mice per cage and switched to water without cefoperazone. C. albicans colonization was measured as described previously [51]. Briefly, 3-4 fecal pellets were collected from each animal into a pre-weighed tube containing PBS. The tube was weighed after collection. Pellets were then homogenized using a microtube vortex, serially diluted, and plated for CFU on YPD-SA.

After 14 days of resting, some mice without $C$. albicans inoculation were given $3.3 \mu \mathrm{L}$ olive oil (Sigma-Aldrich, St. Louis, MO, USA cat. O1514) ( $3 \mathrm{mg}$ ) plus $15 \mu \mathrm{L}$ PBS by gently pipetting into their mouths. Control mice received $15 \mu \mathrm{L}$ PBS. These administrations were given daily for the remainder of the experiment.

Mice were transferred to 2 mice/cage, 17 days post-cefoperazone. 20 days post-cefoperazone treatment, and they were inoculated intraperitoneally with clindamycin (Sigma-Aldrich, St. Louis, MO, USA cat. C5269) $(10 \mathrm{mg} / \mathrm{kg})$. On the next day, the mice were orally inoculated with $C$. difficile spores (3-5 $\times 10^{5}$ spores per mouse). All the mice used in these experiments were shown to be negative for $C$. difficile colonization prior to inoculation with $C$. difficile spores by collecting fecal pellets and plating on pre-reduced TCCFA.

The mice were weighed daily at the same time of day and sacrificed 5 days post-inoculation or when moribund. If the mice exhibited severe signs of illness (extreme inactivity, hunched posture, ruffled fur), they were considered moribund and were sacrificed. The mice were also sacrificed if their weight loss exceeded $20 \%$. Within one experimental trial (i.e., one batch of mice), some of the mice were sacrificed on day 2 post-inoculation for various analyses while the other mice were monitored 
for survival over 5 days. The survival data show the combined results of the mice from multiple experimental trials.

The relative weights were compared using the $t$ test. Survival was compared using the log rank test. Samples of cecum contents were plated on pre-reduced TCCFA to enumerate $C$. difficile.

\subsection{C. difficile Toxin Titer Assay}

African green monkey kidney epithelial cells (Vero cells) (ATCC CCL-81) were seeded in 96-well microtiter plates at a concentration of $4.3 \times 10^{3}$ cells per well in DMEM (Corning Cell Gro, Corning, NY, USA cat. MT10-013CV) with 10\% heat-inactivated fetal bovine serum (Atlanta Biologicals S11150) and 1\% MEM non-essential amino acids (ThermoFisher Scientific, Waltham, MA, USA cat. 11140076) and allowed to adhere for $24 \mathrm{~h}$ at $37{ }^{\circ} \mathrm{C}$ and $5 \% \mathrm{CO}_{2}$ as previously described [51,55]. The cecum contents were weighed and diluted with 10 times the volume of DMEM with 10\% FBS and 1\% MEM non-essential amino acids. Serial three-fold dilutions were made in DMEM with $10 \%$ FBS and $1 \%$ MEM non-essential amino acids, added to adhered Vero cells, incubated for $24 \mathrm{~h}$ at $37^{\circ} \mathrm{C}$ in $5 \% \mathrm{CO}_{2}$ and scored visually at $10 \times$ magnification for cell rounding. The toxin titer is defined as the inverse of the greatest dilution that resulted in 100\% cell rounding.

\subsection{Histology}

Cecum tissue from the mice sacrificed two days post-inoculation with $C$. difficile was fixed in buffered formalin and processed for staining with Hematoxylin and Eosin (H\&E) by the Tufts Comparative Pathology Core facility. Scoring was conducted by a blinded investigator on 30-40 10x fields of view for each tissue. The scores were acquired by dividing the number of fields showing infiltration/inflammation by the total number of fields for that tissue. Each point on the graph represents an individual mouse. A non-parametric t-test was used to compare the groups.

\subsection{Metabolomic Analysis of Murine Cecum Contents}

Cecum contents from the antibiotic-treated mice with or without $C$. albicans pre-colonization were collected, rapidly frozen in a dry ice/ethanol bath and stored at $-80{ }^{\circ} \mathrm{C}$. Samples were shipped to Metabolon (Durham, NC, USA), for metabolite extraction and untargeted metabolomic analysis as described by Metabolon. Briefly, the proteins were precipitated with methanol under vigorous shaking for $2 \mathrm{~min}$ followed by centrifugation. The resulting extract was analyzed using 4 ultra-high-performance LC-MS/MS methods. All methods utilized Waters ACQUITY ultra-high-performance liquid chromatography (UHPLC) and a Thermo Scientific Q-Exactive high resolution/accurate mass spectrometer interfaced with a heated electrospray ionization (HESI-II) source and an Orbitrap mass analyzer operated at 35,000 mass resolution. The MS analysis alternated between the MS and data-dependent $\mathrm{MS}^{\mathrm{n}}$ scans using dynamic exclusion. The scan range varied slightly between the methods but covered 70-1000 m/z. Raw data were extracted, peak-identified and QC processed using Metabolon's hardware and software. Mass spectrometry data were analyzed using MetaboAnalyst 4.0 (University of Alberta, Edmonton, AB, Canada) [56,57].

\subsection{Microbiota Analysis}

The distal portion of the cecum and its contents were dissected from the mice two days post-inoculation with $C$. difficile. The distal tip was dissected and rapidly frozen on dry ice. Microbial DNA was extracted using the QIaAMP PowerFecalPro DNA Kit (Qiagen, Hilden, Germany cat. 12830-50) according to the manufacturer's protocols including the recommended additional steps to ensure the optimal yield of DNA from Gram-positive bacteria. The libraries were prepared from each sample and sequenced as described [58]. Briefly, the PCR amplification of the V4 region of the $16 \mathrm{~S}$ rRNA gene was performed with $515 \mathrm{~F}$ and $806 \mathrm{R}$ primers that included adapters for Illumina sequencing and 12-mer Golay barcodes to allow for multiplexing. Two hundred and fifty bp paired-end sequencing was performed using an Illumina MiSeq according to the manufacturer's protocols. Base calling 
was performed using CASAVA 1.8 and the resulting fastq files were used for downstream analysis using QIIME 2 (2018.8) [59]. Raw sequences were demultiplexed and filtered using the q2-demux plugin followed by DADA2 [60] for denoising (q2-dada2). Amplicon sequences were aligned using mafft [61] (q2-alignment). Phylogeny trees were constructed using the de novo phylogenetic tree from fasttree2 [62] (q2-phylogeny). Alpha-diversity metrics (Shannon, Chao1, and Simpson) and Beta-diversity (weighted UniFrac [63]) were estimated using the q2-diversity. Principal coordinate analysis (PCoA) was used to summarize the weighted UniFrac distance matrix. PERMANOVA analysis was performed using QIIME2. The operational taxonomic units (OTUs) were determined by aligning reads to the Greengenes Database (version 13_8) at 99\% identity [64]. Feature tables describing the relative abundance of bacterial taxa were used for the analysis of diversity within each sample.

The total levels of bacteria per cecal tip sample were measured by qPCR using eubacterial primers (Supplementary Table S1). The qPCR reactions were conducted using SYBR Green PCR Master Mix (Applied Biosystems, Beverly, MA, USA cat. 4364346) and a LightCycler 480 II (Roche, Basel, Switzerland) instrument. The normalized abundance of bacterial genera was calculated by multiplying the fraction of total reads for a genus by the total level of bacteria per mg of cecum sample (in arbitrary units).

\subsection{Cytokine Gene Transcription}

For the measurement of cytokine gene transcription, the mice were sacrificed prior to or two days post-inoculation with C. difficile and the colon tissue was frozen in RNALater (Invitrogen, Carlsbad, CA, USA cat. AM7021) at $-80^{\circ} \mathrm{C}$. RNA was purified with Trizol (Invitrogen, Carlsbad, CA, USA cat 15596026) extraction and column purification, using the Ambion Purelink RNA mini kit (Invitrogen, Carlsbad, CA, USA cat 12183018A). DNA was eliminated with on-column DNase treatment. cDNA preparation with Superscript III (Invitrogen, Carlsbad, CA, USA cat 18080051) was performed using the manufacturer's protocol. The qRT-PCR reactions were performed as described above for qPCR. The triplicate samples were measured; the controls lacking a template did not yield products. Standard curves were generated and all the results were normalized to the level of GAPDH transcription in each sample. The primers are listed in Supplementary Table S1.

\subsection{C. difficile Gene Transcription}

For the growth curves of the $C$. difficile cells in the presence or absence of oleic acid diluted in ethanol, TY broth was used. Overnight cultures were diluted to an $\mathrm{OD}_{600}$ of 0.02 into pre-reduced TY broth containing $0.05 \mathrm{mM}$ oleic acid, $0.6 \mathrm{mM}$ oleic acid or the vehicle (ethanol). The addition of oleic acid did not result in a change in the $\mathrm{pH}$ of the broth. The cultures were incubated at $37^{\circ} \mathrm{C}$ in an anaerobic chamber. The samples were taken at various times to measure the $\mathrm{OD}_{600}$ or plate for CFU from vegetative cells and spores using pre-reduced BHIS plates (3.7\% brain heart infusion extract, $0.5 \%$ yeast extract, $0.1 \% \mathrm{~L}$-cysteine, $1.5 \%$ agar [65]). The samples were taken at $8 \mathrm{~h}$ or $24 \mathrm{~h}$, mixed with RNAprotect, centrifuged at $21,000 \mathrm{~g}$ for $10 \mathrm{~min}$ at $4{ }^{\circ} \mathrm{C}$ and the cell pellets were frozen at $-80^{\circ} \mathrm{C}$.

For the analysis of epithelium-associated bacteria, the mice were sacrificed two days post-inoculation with $C$. difficile spores. The ceca were removed, the cecum wall was washed twice in RNAprotect and the epithelium was scraped into RNAprotect using a glass slide. This sample was centrifuged at $4000 \mathrm{~g}$ for $7 \mathrm{~min}$ and the pellets were frozen at $-80^{\circ} \mathrm{C}$.

The RNA was extracted from these samples by bead beating in Trizol with $0.1 \mathrm{~mm}$ zirconia/glass beads, $3 \times 1 \mathrm{~min}$ in a Biospec Bead Beater 24, followed by purification using the PureLink mini RNA extraction kit. The cDNA was prepared with random priming and MultiScribe Reverse Transcriptase using the Applied Biosystems High Capacity cDNA synthesis kit. The primers were designed using Primer-BLAST to identify the primers predicted to lack targets in other bacteria from the Refseq representative genomes database. The PCR products were sequenced to verify the specificity of the primers. 
Gene transcription was measured by quantitative RT PCR using an Applied Biosystems StepOne System. The transcription of $r p o A$ was used to normalize the transcription of the genes of interest. Primers failed to yield products when the cDNA derived from uninfected cecum epithelium, extracted and processed as above, was used as the template (Supplementary Figure S1).

To increase the ability to detect the $C$. difficile gene transcription in samples scraped from infected murine ceca, a pre-amplification step was included. A single primer specific for the $C$. difficile gene of interest and upstream of the primer pair used for PCR amplification was designed using Primer-BLAST. Since all cDNA molecules are copied from the positive, sense (mRNA) strand, they represent the negative strand. Therefore, the upstream primer was a forward primer and would prime from the cDNA copies. Twelve cycles of conventional PCR were performed using a mix of single gene specific primers. The pre-amplified cDNA was then used as template for qRT PCR. The experiment shown in Supplementary Figure S2 shows that the samples retained their quantitative relationship and that gene transcription was detected with a higher sensitivity after pre-amplification. All $C$. difficile genes other than $t c d B$ and $t c d A$ required pre-amplification to be detected in the samples of scraped epithelia.

\subsection{Statistical Analysis}

Statistical analyses were performed using GraphPad Prism (San Diego, CA, USA), Excel or Metaboanalyst (University of Alberta, Edmonton, AB, Canada).

\section{Results}

\subsection{Altered Levels of Unsaturated Fatty Acids and Other Lipid Species in the Cecum Contents of C. albicans-Colonized Mice}

To determine the effect of $C$. albicans colonization on the metabolite milieu of the intestinal tract, mice were treated with antibiotic to increase their susceptibility to CDI, but instead of receiving spores, the mice were sacrificed and the contents of the cecum were collected and rapidly frozen. The antibiotic regiment consisted of 10 days of exposure to cefoperazone in drinking water while being co-housed, followed by oral inoculation with C. albicans (or not) as described below (Figure 2A). The mice were then rested for 20 days in smaller groups (4/cage with C. albicans-colonized mice separated from the non-colonized mice) with water lacking antibiotics. Fecal pellets collected during the resting period were plated to detect $C$. albicans CFU. All the mice were positive for $C$. albicans on day 6 or day 17 post-inoculation ((Supplementary Figure S3) consistent with the previous demonstrations of colonization in this model [16,51]. Mice were given clindamycin $(10 \mathrm{mg} / \mathrm{kg}$ body weight) by intraperitoneal injection and sacrificed on the following day. Eight mice per group, taken from two different experimental trials, were analyzed. The cecum contents were analyzed using LC-MS/MS by Metabolon as described and the results were analyzed using Metaboanalyst [56,57] (Figure 1A). Of the 595 total compounds analyzed, 44 showed a fold change $\geq 1.3$ (colonized/uncolonized mouse ceca) and a $p \leq 0.05$ (Supplementary Table S2).

To identify the compounds from pathways enriched in ceca of $C$. albicans-colonized mice, we used the pathway enrichment tool within MetaboAnalyst. Analyzing only statistically significantly different compounds revealed no known pathways, but including compounds that showed a trend towards significance $(p<0.1)$ allowed the detection of one pathway: five compounds in the linoleic $(\mathrm{C} 18: 2)$ and linolenic (C18:3) acid metabolism pathway (Figure 1A, black triangles, Figure 1B) were present at higher levels in C. albicans-colonized mice. All three 18-carbon non-esterified unsaturated fatty acids showed trends toward higher levels in C. albicans-colonized mice (Figure 1C-E). Furthermore, the increase in lyso-phospholipids (Figure 1F,G) could indicate a hydrolysis of phospholipids and the release of non-esterified fatty acids while the decrease in hydroxy fatty acids (Figure 1H,I) could indicate a reduced conversion of fatty acids into other forms. Therefore, the results showed altered levels of lipid compounds, including non-esterified, unsaturated fatty acids, in the cecum contents of C. albicans-colonized mice. 


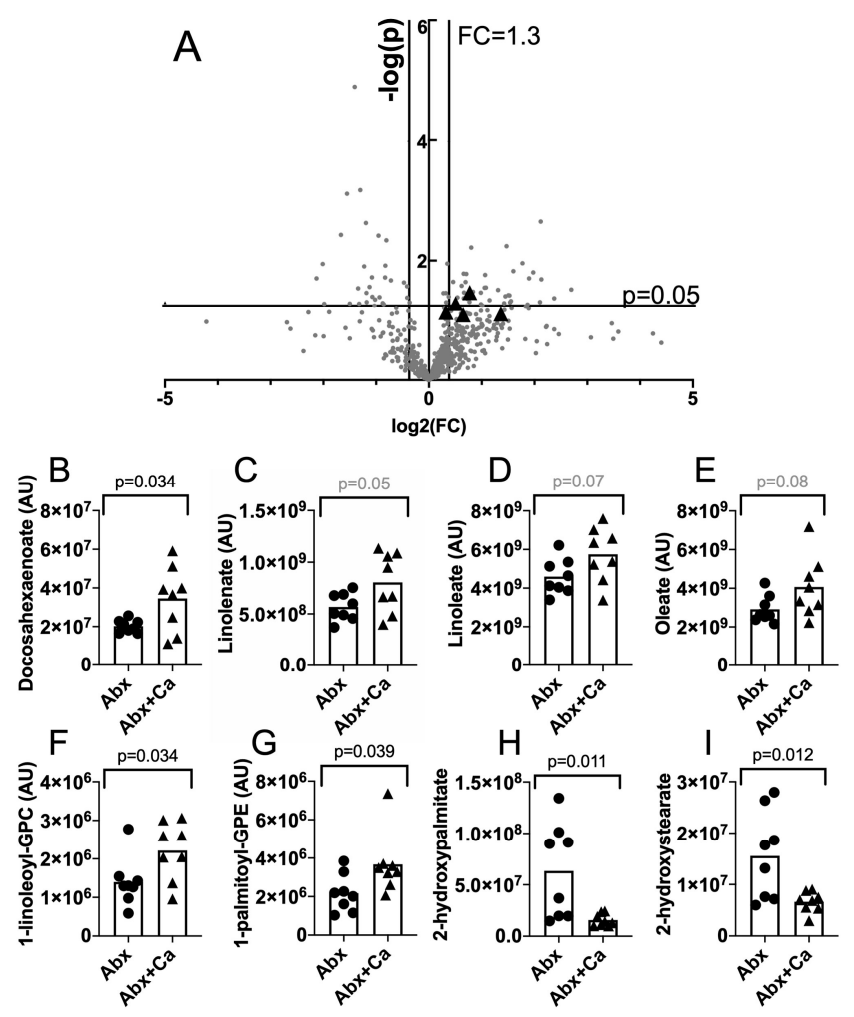

Figure 1. Untargeted metabolomic analysis of the cecum contents reveals higher levels of compounds related to linolenic acid metabolism in C. albicans-colonized mice. Mice were treated with antibiotics as described in Materials and Methods (cefoperazone, 10 days, rest 20 days, clindamycin ip). On the day following clindamycin treatment, the mice were sacrificed and the contents of the cecum were collected and frozen rapidly in dry ice/ethanol. These samples were analyzed by Metabolon using LC-MS/MS. Results were analyzed using Metaboanalyst. (A) Of the 595 compounds identified by Metaboanalyst, 590 are shown in a volcano plot $(\log 2(\mathrm{FC})$ versus $-\log 10(p))$. The black triangles show the compounds in the enriched, linoleic and linolenic acid metabolism pathway. (B-I) Compounds showing altered levels or a trend toward altered levels in C. albicans-colonized mice. Each symbol shows the results from an individual animal. Bar shows the mean. Compounds (B-D) are in the linoleic and linolenic acid metabolism pathway. Circles, antibiotic treated, uncolonized; triangles, antibiotic treated, C. albicans colonized.

\subsection{Protective Effects of Olive Oil Feeding on Antibiotic-Treated Mice Challenged with C. difficile Spores}

We proposed that the levels of lipid compounds in the GI tract influence the course of CDI in antibiotic-treated mice. To initiate the test of this hypothesis, we analyzed the effects of increasing levels of unsaturated fatty acids and other lipid compounds through feeding. The mice were treated with cefoperazone and clindamycin as described above and shown in Figure 2A. Importantly, no mice were given C. albicans for this set of experiments. After two weeks of resting post-cefoperazone treatment, the mice were orally administered a modest amount of olive oil daily for 1 week prior to the C. difficile challenge and continuing to the end of the experiment. The timeline of this experiment is shown in Figure 2A. In a pilot experiment, the mice received either olive oil (composed predominantly of triglycerides containing oleic acid (C18:1)) or fish oil (source of long-chain poly-unsaturated fatty acids such as DHA), orally with PBS (Supplementary Table S3). The results of this pilot experiment suggested that larger amounts of both oils had some effect and olive oil had a slightly stronger effect. Although fish oil contains long-chain poly-unsaturated fatty acids, some of its components have anti-inflammatory effects and fish oil administration is sometimes protective and sometimes not protective against infectious challenge [66]. Olive oil, in contrast, is composed primarily of triglycerides 
containing oleic acid (C18:1), a compound that showed a trend towards higher levels in the ceca of C. albicans-colonized mice (Figure 1E).
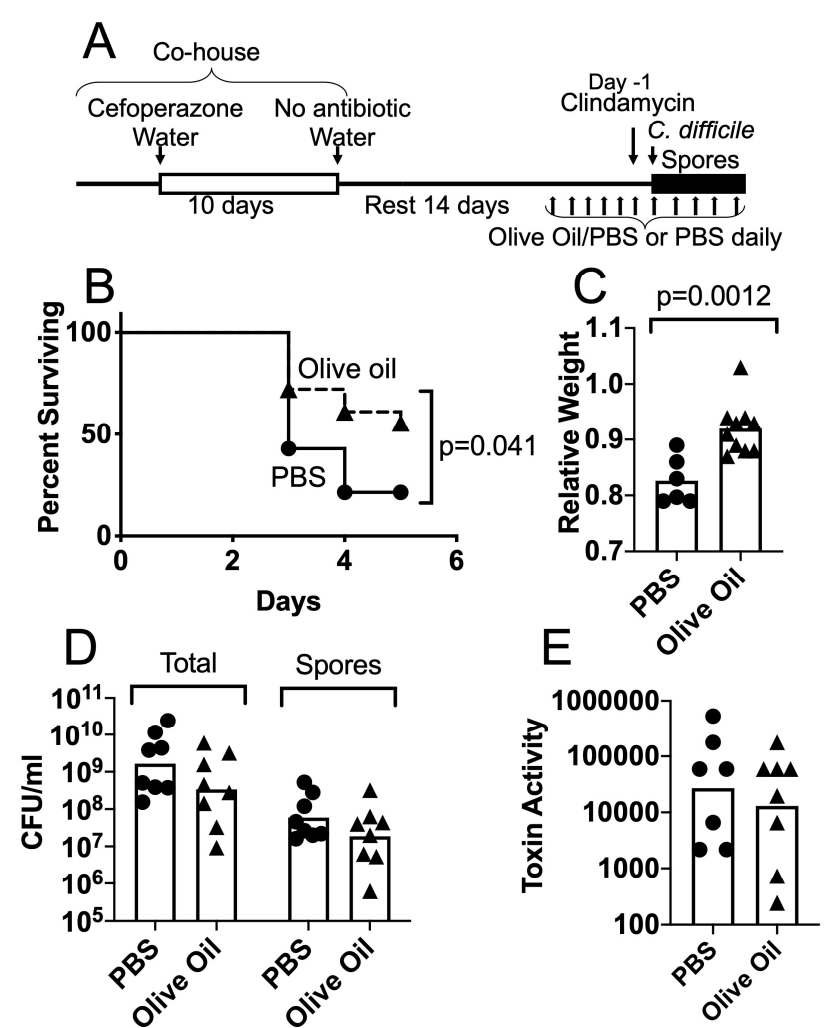

Figure 2. Olive oil feeding enhances the survival of the challenge with $C$. difficile spores in the antibiotic-treated mice. Outline of the mouse regimen is shown in (A). The C57BL/6 mice were co-housed in a large cage and received antibiotics as described in the Materials and Methods (cefoperazone 10 days). Mice were then transferred to the standard size cages with water without additives, rested 14 days, and then received a daily oral administration of olive oil with PBS or PBS only. Mice received clindamycin ip and the following day received $C$. difficile spores $\left(3-5 \times 10^{5}\right.$ spores of strain UK1, a NAP1/027/BI human epidemic strain) by oral inoculation. (B) Survival of the mice was monitored for 5 days post-inoculation with spores (PBS, $n=14$; Olive oil, $n=18$; log rank test $p=0.041$ ). (C) Panel shows the relative weights of the surviving mice on day 3 post-inoculation $(t$ test $p=0.0012)$. (D) C. difficile bacteria were enumerated by plating the homogenized cecum contents collected from the mice sacrificed on day 2 post-inoculation. Homogenates were plated on a TCCFA medium (total) or heated at $60^{\circ} \mathrm{C}$ for $10 \mathrm{~min}$ and plated (spores). (E) C. difficile toxin activity in the cecum contents from the mice sacrificed on day 2 post-inoculation was measured using a cell-rounding assay. The inverse of the greatest dilution that yielded $100 \%$ cell rounding is plotted. Circles, antibiotic treated, uncolonized; triangles, antibiotic treated, C. albicans colonized.

Further studies of olive oil administration showed that this treatment had a protective effect. The mice were treated as illustrated in Figure 2A and were fed either $3.3 \mu \mathrm{L}$ olive oil with PBS, or PBS alone. This treatment did not lead to significant weight gain in the olive oil-fed mice (Supplementary Figure S4). After the administration of clindamycin (10 mg/kg ip), the mice were challenged with 3-5 $\times 10^{5}$ spores of $C$. difficile strain UK1, a NAP1/027/BI human epidemic strain, and weight loss and survival were monitored for 5 days post-inoculation. As shown in Figure 2B, the mice receiving olive oil treatment showed evidence of improved survival relative to the mice receiving PBS alone. Of the 18 mice that were fed with olive oil, eight died, none were sacrificed when moribund or due to weight loss, and 10 survived. Of the 14 mice that did not receive olive oil, seven died, four were sacrificed due to weight loss, none were sacrificed when moribund and three survived. The survival curves 
were significantly different $(p=0.041$, Kaplan-Meier log rank test). The relative weights of mice were determined on the days following the $C$. difficile challenge (Supplementary Figure S5). The relative weights of the surviving mice on day 3 post-challenge with spores were significantly different, with the oil-fed mice showing a higher weight, consistent with the enhanced resistance to CDI (Figure 2C, $t$ test $p=0.0012$ ).

To analyze the disease parameters, the mice were treated as shown in Figure 2A and then sacrificed two days post-inoculation with spores. The total C. difficile $\mathrm{CFU} / \mathrm{gm}$ cecum contents or spore $\mathrm{CFU} / \mathrm{gm}$ cecum contents did not differ significantly between the mice with or without olive oil treatment (Figure 2D). The toxin activity measured in cecum contents did not differ significantly between the two groups of mice (Figure 2E).

We also analyzed the $C$. difficile gene transcription in the bacterial cells recovered from infected mice. The mice were treated as shown in Figure 2A and sacrificed two days post-challenge with spores. The ceca were dissected, opened and washed twice in RNA protect. The washed cecum wall was then scraped into RNAprotect to recover the epithelium and enrich for epithelium-associated bacteria. The RNA was extracted from the samples and the $C$. difficile gene transcription was measured using RT PCR as described in the Materials and Methods. The $C$. difficile toxin genes $t c d B$ and $t c d A$ were transcribed at high enough levels to be detected in these mixed samples. Other $C$. difficile genes were poorly expressed and a pre-amplification method was used to increase the sensitivity of detection. This pre-amplification consisted of 12 rounds of PCR using only one sense strand primer and increased the sensitivity while retaining the quantitative assessment of gene transcription (Supplementary Figure S2). The transcription of the toxin gene $t c d B$ was significantly lower in epithelium-associated C. difficile cells from olive oil-fed mice (Figure $3 \mathrm{~A}, t$ test $p=0.0391$ ). The transcription of $t c d A$ showed a trend towards lower transcription in olive oil-fed mice ( $t$ test $p=0.0642$ ). Other genes such as fliC or mcsA (CDR20291_0013) did not show significant differences in their transcription. These results indicate that although the overall toxin levels in the cecum contents were not significantly different, the possible ability to produce toxin (specifically TcdB) by C. difficile cells in the vicinity of the epithelium was affected by the treatment with olive oil. These results are consistent with the observation that olive oil feeding reduced the virulence of $C$. difficile, but this reduction in virulence is most likely multifactorial.

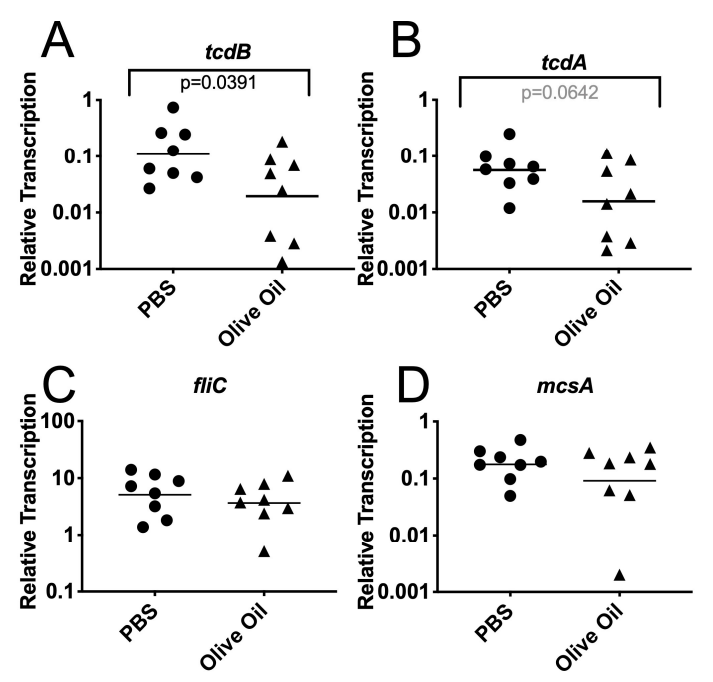

Figure 3. Reduced transcription of $t c d B$ in the epithelium-associated C. difficile cells harvested from the olive oil-fed mice. Mice were treated as described in Figure 2A. On day 2 post-inoculation with spores, the mice were sacrificed and their cecum was removed. The cecum was opened, washed with RNAprotect and the wall was scraped into RNAprotect to recover the epithelium and enrich for associated bacteria. RNA was extracted and the gene transcription measured in CDNA using qRT PCR. Transcription of (A) $t c d B$, (B) $t c d A$, (C) fliC, and (D) $m c s A$ was normalized using rpo $A$ transcription. Circles, antibiotic treated, uncolonized; triangles, antibiotic treated, C. albicans colonized. 
Histological analysis and the scoring of cecum and colon tissue from olive oil-fed or control mice sacrificed two days post-inoculation with spores showed regions of infiltration and edema, consistent with the damage due to $C$. difficile infection and no overall difference between the two treatment groups (Supplementary Figure S6).

The cecal microbiota of the mice treated with cefoperazone followed by clindamycin and then given olive oil or PBS and finally challenged with $C$. difficile spores was analyzed (Figure 4). The mice were sacrificed two days post-inoculation with spores and the cecum tip was harvested; DNA was extracted as described in the Materials and Methods. The bacterial community composition was characterized by sequencing the V4 region of the 16S rRNA gene and analyzed using QIIME 2 (2018.8) [59] as described in the Materials and Methods. The principal coordinate analysis (PCoA) of the weighted UniFrac distance for the bacterial communities in the PBS versus the olive oil mouse ceca treatment is shown in Figure 4A. The PERMANOVA analysis of these results did not detect a statistically significant difference between the treatment groups $(p=0.311)$. The total levels of bacteria were measured using qPCR and universal 16S rRNA primers (Supplementary Table S1). The total number of bacteria detected per milligram of cecum sample was not significantly different between the mice that received PBS versus the mice that received olive oil (Figure 4B).

To test for possible differences in the specific genera within the microbiota between the PBS and olive oil-fed groups, we compared the abundance of bacterial genera, normalized to the total level of bacteria per milligram of cecum sample. Normalization was used to account for the differences in the total levels of bacteria per mg of sample. All the bacterial genera with a median fraction greater than 0 in at least one of the two groups were included in order to identify the consistently observed genera (Figure $4 \mathrm{C}$ ). These mice had received multiple antibiotic treatments and were infected with C. difficile, and they were colonized with relatively few genera. We detected a total of 44 genera and 16 exhibited a median greater than 0 in at least one group. The normalized abundance of the genera was compared between the PBS or the olive oil-fed mice using an unpaired $t$-test. None of the genera identified displayed significant differences. Additionally, we did not detect any significant differences in the phyla composition between the groups (Figure 4D).

To detect a possible effect of olive oil on the relative abundance of rare taxa, we measured the community diversity using the Chao1 estimator (Supplementary Figure S7A). The microbiota did not exhibit increased diversity between the PBS or olive oil treatment when analyzed using the Chao1 or other measures (e.g., Simpson index and Shannon index, Supplementary Figure S7B,C). The above results demonstrate that the concentration of olive oil supplementation did not have significant effects on the host microbiota composition and diversity analyzed at the genus level. 

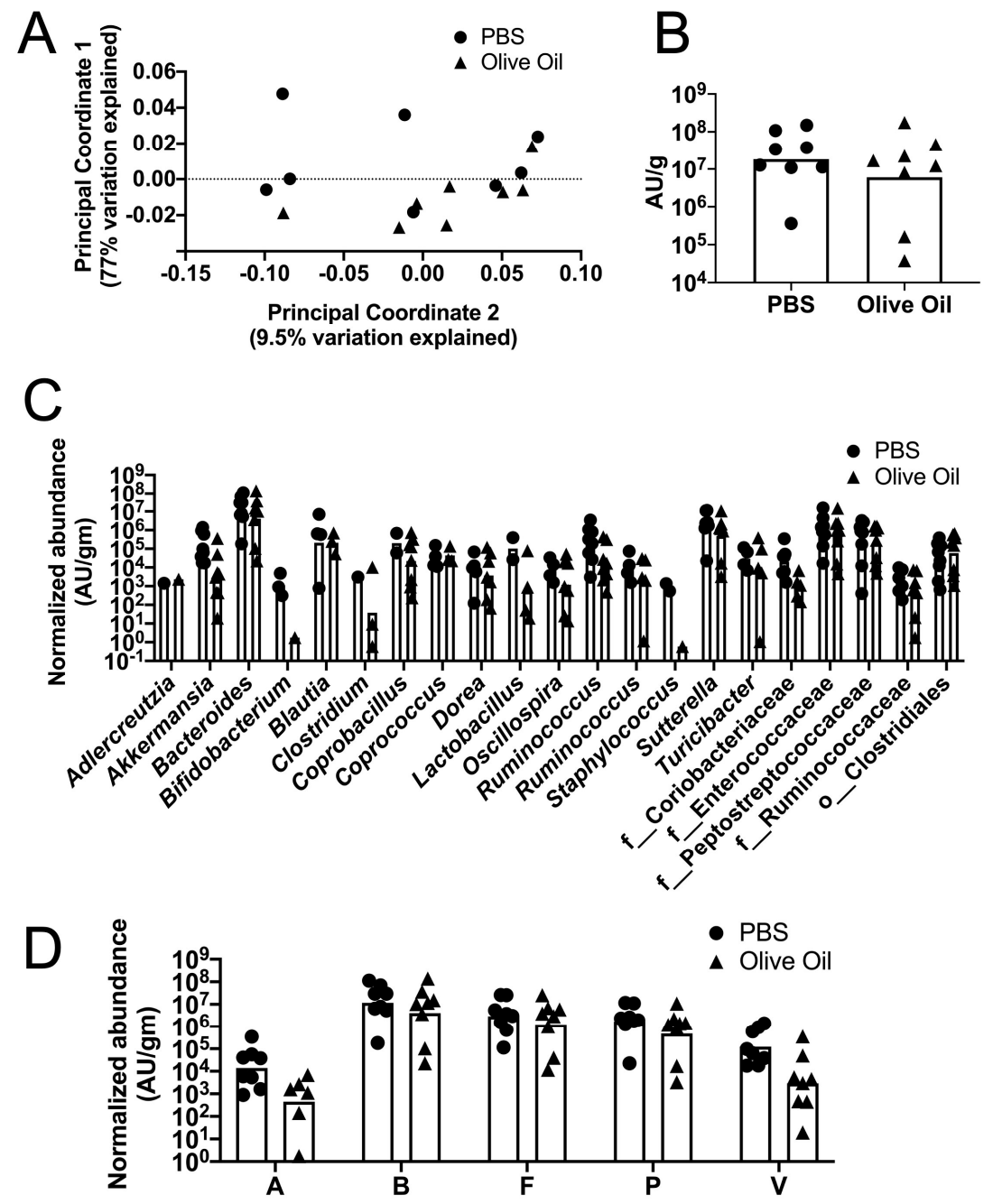

Figure 4. Analyses of the cecal bacterial communities in the PBS or olive oil-fed mice infected with C. difficile. Mice were treated as described in Figure 2A. On day 2 post-inoculation with $C$. difficile spores, the mice were sacrificed and their ceca were removed. Bacterial composition was analyzed as described in the Materials and Methods with QIIME 2. (A) Weighted UniFrac distances were used to perform a Principal coordinate analysis. (B) Total levels of bacteria per cecal tip sample were measured by qPCR using eubacterial primers and normalized to milligrams of cecum sample used for DNA extraction. Bar indicates geometric mean. (C) Normalized abundance per mg of cecum sample for the bacterial genera in the cecal microbiota ( $n=8$ mice per group). (D) Phyla are abbreviated as follows $\mathrm{P}=$ Proteobacteria; $\mathrm{V}=$ Verrucomicrobia; $\mathrm{A}=$ Actinobacteria; $\mathrm{F}=$ Firmicutes; $\mathrm{B}=$ Bacteroidetes. The black circles indicate the PBS-treated, $C$. difficile-challenged mice. The black triangles indicate the olive oil-fed, $C$. difficile-challenged mice.

Pre-colonization with the commensal fungus $C$. albicans resulted in higher levels of transcription of the cytokine gene Il17a in colon tissue harvested from the antibiotic-treated, $C$. difficile-challenged mice [51]. To determine whether the olive oil administration similarly altered the host cytokine response to $C$. difficile spore challenge, we analyzed the cytokine gene transcription in colon tissue taken either before or 2 days after inoculation. RNA was extracted from these tissues and gene transcription was measured in cDNA using quantitative real-time PCR (qRT PCR). Differences between the olive oil-fed and the PBS-fed mice in the transcription of genes encoding IL-17A, IL-23 and TNF- $\alpha$ were not detected either before or after spore challenge (Figure 5). Transcription of Il17a and Tnf $\alpha$ increased in response to the $C$. difficile challenge. 


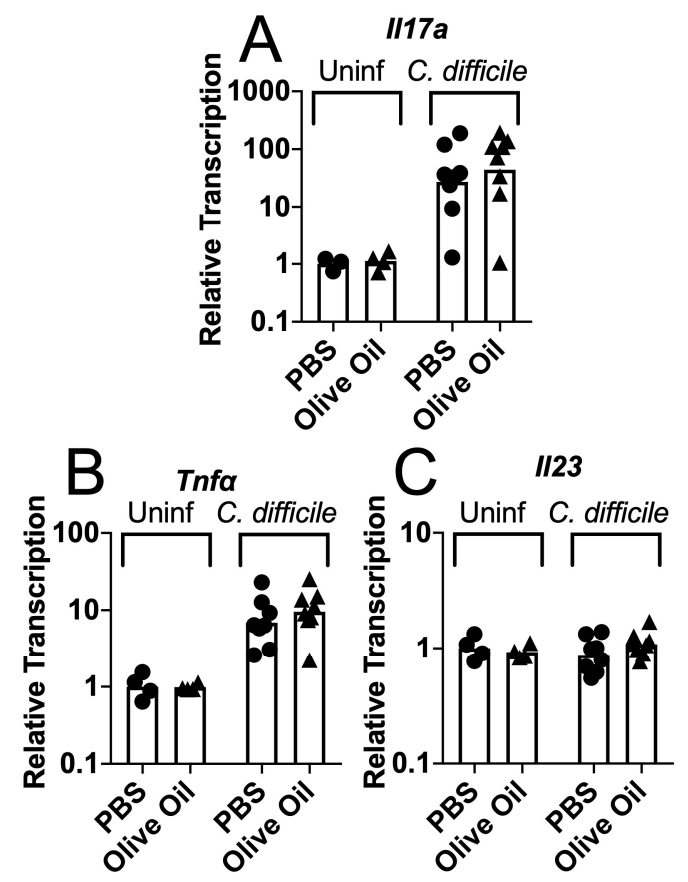

Figure 5. Cytokine gene transcription in the C. difficile-challenged, olive oil-fed mice. Mice were treated as described in Figure 2A. Before or on day 2 post-inoculation with spores, the mice were sacrificed and their colons were removed and stored in RNALater. RNA was extracted and the gene transcription was measured in cDNA by qRT PCR. Transcription of (A) Il-17a, (B) Tnf $\alpha$, and (C) Il-23 was normalized to transcription of Gapdh. Circles, antibiotic treated, uncolonized; triangles, antibiotic treated, C. albicans colonized.

In summary, we observed the reduced virulence of $C$. difficile in antibiotic-treated mice fed olive oil and a reduction in the toxin gene transcription in the epithelium-associated $C$. difficile bacteria. Changes in the composition of bacterial microbiota or the cytokine responses of the host were not detected. These results are consistent with the model in which changes in the metabolome due to C. albicans colonization or olive oil feeding can ameliorate the course of CDI.

\subsection{Effects of Oleic Acid on C. difficile Growth and Toxin Gene Transcription}

These results showed that the olive oil treatment did not exert a strong effect on the GI tract environment (bacterial microbiota, cytokine responses), raising the possibility that the treatment had a direct effect on $C$. difficile bacteria. Olive oil is primarily composed of triglycerides of oleic acid, which are hydrolyzed in the upper GI tract. We therefore examined whether non-esterified oleic acid had a direct effect on the physiology of $C$. difficile.

Gene transcription and the growth of $C$ difficile in pre-reduced TY broth with or without oleic acid was analyzed at different concentrations. The exponential phase growth of $C$. difficile in TY broth containing $0.6 \mathrm{mM}$ oleic acid $(0.017 \% w / v)$ was not markedly altered in comparison to cultures containing the vehicle control (Figure 6A). However, when the cells transitioned to the stationary phase, a decrease in optical density was observed for the cultures grown with oleic acid. The decrease became more pronounced at $24 \mathrm{~h}$ of culturing. Plating cultures after $25 \mathrm{~h}$ of growth showed that $\mathrm{CFU} / \mathrm{mL}$ declined in an oleic acid concentration-dependent manner (Figure 6B). Additionally, the spore levels after $51 \mathrm{~h}$ of culture were measured and found not to be affected by oleic acid (Supplementary Figure S8). These results demonstrated that while oleic acid did not reduce the growth rate of $C$. difficile, it compromised the viability of $C$. difficile bacterial cells during the stationary phase. 


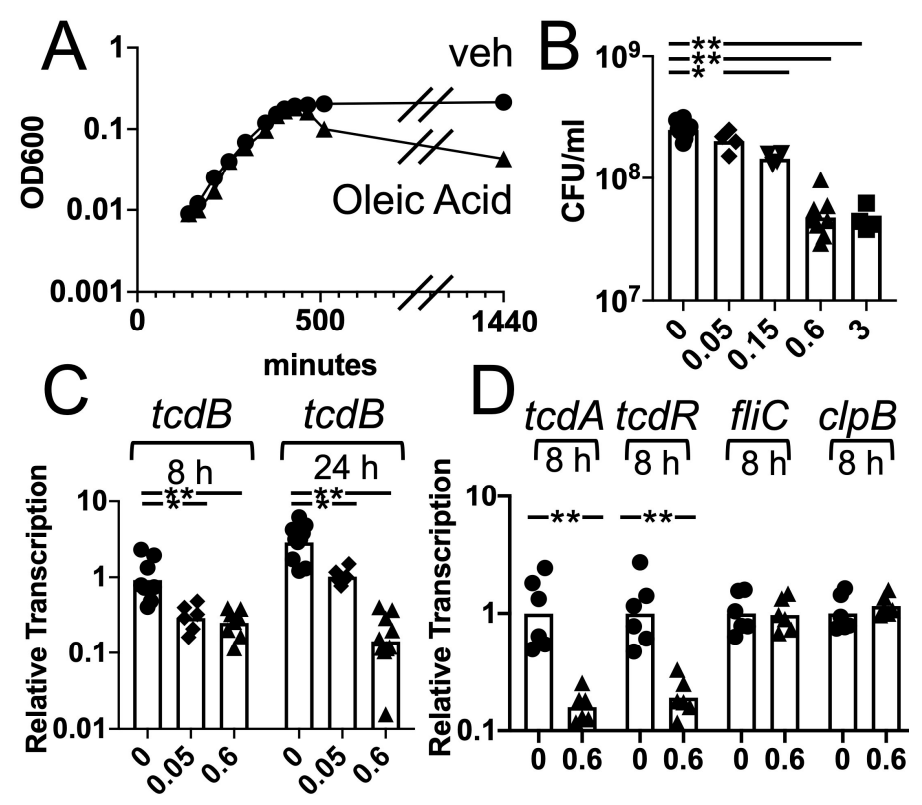

Figure 6. Altered survival and gene transcription in the C. difficile cells grown in the presence of oleic acid. C. difficile cells of the strain UK1 were grown overnight in a pre-reduced TY ( $3 \%$ bacto tryptose, $2 \%$ yeast extract, $0.1 \%$ thioglycolate, $\mathrm{pH} 7.4$ ) broth. The cultures were back diluted to $\mathrm{OD}_{600}=0.02$ and grown in pre-reduced TY broth supplemented with ethanol or with oleic acid in ethanol. Final concentrations of oleic acid varied as shown in the figure $(0,0.05,0.15,0.6$ and $3 \mathrm{mM})$. (A) Growth in the presence of $0.6 \mathrm{mM}$ oleic acid or the ethanol vehicle was monitored by taking samples at various times and reading $\mathrm{OD}_{600}$. One experiment representative of 3 independent experimental trials is shown. (B) Survival after $25 \mathrm{~h}$ of culture with the indicated concentration of oleic acid was measured by plating. Each symbol indicates the results from an independent culture and the bar is the geometric mean. (one-way ANOVA with post hoc Dunnett's multiple comparisons test ${ }^{*}, p=0.003 ;{ }^{* *}, p<0.0001$ ). (C) C. difficile cells grown for 8 or $24 \mathrm{~h}$ with the indicated concentration of oleic acid were harvested in RNAprotect. RNA was extracted and the gene transcription was measured in cDNA and normalized to rpoA transcription. Each symbol indicates results from an independent culture and the bar is the geometric mean. (one-way ANOVA with post hoc Dunnett's multiple comparisons test $*, p<0.02 ;{ }^{* *}$, $p<0.0003$ ). (D) Samples were treated as in (C). Each symbol indicates the results from an independent culture and the bar is the geometric mean. ( $t$ test, $\left.{ }^{* *}, p<0.0003\right)$.

Furthermore, growth in the media containing oleic acid resulted in the reduced transcription of the toxin genes. C. difficile cells were grown in a pre-reduced TY broth supplemented with oleic acid at various concentrations or vehicle control and the bacteria were harvested using RNAprotect. RNA was extracted and the gene transcription was measured in cDNA. Transcription of $t c d B$ was reduced in the presence of either $0.05 \mathrm{mM}$ or $0.6 \mathrm{mM}$ oleic acid grown for 8 and $24 \mathrm{~h}$ of culture (Figure 6C) in comparison with the vehicle control. Similar effects were observed at 1 and $9 \mathrm{mM}$ oleic acid (Supplementary Figure S9). Transcription of $t c d A$ and $t c d R$ showed a similar reduction (Figure $6 \mathrm{D}, 8 \mathrm{~h}$ of culture with or without $0.6 \mathrm{mM}$ oleic acid). In contrast, other genes such as fliC and $\operatorname{clpB}$ (CDR20291_1933) were not changed by the presence of oleic acid (Figure 6D, $8 \mathrm{~h}$ of culture, $0.6 \mathrm{mM}$ oleic acid). These results support the model in which growth in the presence of oleic acid reduced the toxin gene transcription and stationary phase survival of $C$. difficile. Both of these effects could contribute to reducing the virulence of $C$. difficile in the olive oil-fed mice.

\section{Discussion}

The host metabolic milieu is influenced by a variety of factors, including resident microbiota. Our studies show that the opportunistic pathogenic fungus and common colonizer of the gastrointestinal tract, C. albicans, influences the metabolic composition of the host gastrointestinal tract. This study 
focused on lipid species because compounds in the linoleic and linolenic acid metabolism pathway were enriched among compounds showing at least a trend towards higher levels in C. albicans-colonized mice (Figure 1). Previously, we have shown that the pre-colonization of antibiotic-treated mice with C. albicans protects against a lethal C. difficile challenge [51]. This protection appeared to be conferred by an increase in $I L-17$ transcription induced by the presence of $C$. albicans. Furthermore, we were able to recapitulate the protection without $C$. albicans pre-colonization by exogenous IL-17 administration. In our current study, we show that olive oil feeding is able to protect mice from lethal CDI, to a lesser extent than C. albicans colonization, without inducing an increase in $I L-17$ transcription. Combined, these studies highlight a potential protective role for C. albicans during CDI by both modifying the metabolic milieu and inducing host immunological responses, which are antagonistic to $C$. difficile.

Although these studies suggest a protective role for $C$. albicans during CDI, other groups have reported opposite effects. Panpetch and co-workers recently reported that the presence of C. albicans during CDI increased virulence in a murine model [67]. In these studies, the authors introduced C. albicans one day before $C$. difficile infection and observed disease exacerbation presumably due to increased inflammatory responses [67]. The conflicting results from these murine studies are likely due to the timing of Candida acquisition. It has previously been shown that $C$. albicans is able to colonize and shape the host gastrointestinal microbiota [68,69]. Moreover, long-term colonization allows $C$. albicans to become integrated into the host microbiota and shape its microbial, metabolic and immune environment. Overall, the conflicting results from the animal studies and clinical observations described above probably reflect a multitude of factors including the distinct times of acquisition of the two organisms since timing affects disease outcome in animal studies, differences in historic antibiotic usage in each patient, and differences in microbial strains [70]. Additionally, in clinical observation studies, the presence of Candida colonization before CDI was not assessed.

In our current study, olive oil feeding reduced the killing of antibiotic-treated mice in response to $C$. difficile spore challenge (Figure 2). As described above, the toxin production by $C$. difficile induces severe damage to the host gastrointestinal tract. Olive oil feeding resulted in lower levels of transcription of the toxin gene $t c d B$ in bacteria associated with the cecum epithelium (Figure $3 \mathrm{~A}$ ). Furthermore, the culture of $C$. difficile in the presence of oleic acid, a primary component of olive oil, resulted in the reduced transcription of $t c d B$ and reduced the viability of $C$. difficile cells in the stationary phase (Figure 6). These findings support the model in which increased levels of unsaturated fatty acids in the lower gastrointestinal tract reduce the virulence of $C$. difficile cells, through direct effects on gene transcription in bacteria associated with the epithelium, contributing to the ability of mice to survive an otherwise lethal challenge with $C$. difficile spores.

Oleic acid has been shown to affect a variety of microorganisms [71,72]. More recently, Subramanian and co-workers showed that oleic acid inhibits the virulence and biofilm formation of $C$. albicans [73]. In these studies, oleic acid was shown to disrupt $C$. albicans biofilms and significantly inhibit filamentation. Additionally, oleic acid induced oxidative stress responses in C. albicans and displayed broad effects, which included the modification of the ergosterol composition on the fungal cell membrane although the exact effects in an animal model are not known. A related unsaturated fatty acid, linoleic acid, has recently been shown to enhance Salmonella enterica gastrointestinal colonization dissemination to the spleen in a murine model [74]. Both of these studies suggest that lipids could play a complex role in the host gastrointestinal tract, providing beneficial or detrimental effects to the host, possibly influenced by the overall microbiota composition and state of the host immune response.

Interestingly, the levels of lipid species have been shown to rise during CDI. In a murine model, Fletcher et al. characterized the gut metabolome during active infection [75]. These studies showed large metabolic changes during disease. A variety of lipid species increased in abundance in the cecum $30 \mathrm{~h}$ post challenge with $C$. difficile. The lipids identified were derived from the host and their increase in abundance was presumably due to toxin damage caused by TcdA and TcdB. Additionally, the increase in abundance of lipids was accompanied by inflammatory mediators. The results reported here suggest that responses of $C$. difficile to lipid species could influence the course of infection. 
Other results have shown that feeding a high-fat diet coincident with antibiotic treatment increases susceptibility to CDI $[76,77]$. The regimen used in our studies was distinct from those previously described. Olive oil feeding was initiated two weeks after the antibiotic treatment and relatively low levels were used. Mice did not gain significant weight due to the oil feeding (Supplementary Figure S3). Furthermore, high-fat diet feeding typically has a strong effect on gut microbiota composition whereas the olive oil feeding used here had a minimal effect (Figure 4). The differences in the amount of fat given and the timing of the intervention probably account for the difference in the effects of high-fat diets versus oil feeding.

The mechanism for the effects of oleic acid on $t c d B$ transcription is unknown but in the soil bacterium Bacillus subtilis, DNA binding by the B. subtilis regulatory protein BscR is inhibited by oleic acid in a gel shift assay [78], showing that DNA binding activity can be altered by a fatty acid. In addition, $t c d B$ and $t c d A$ are regulated by the sporulation regulator Spo0A $[79,80]$ and the histidine kinases that activate Spo0A $[80,81]$. The activity of B. subtilis KinA (one of the B. subtilis sporulation histidine kinases) is directly inhibited by oleic acid [82]. Therefore, oleic acid could be directly affecting a regulator of $t c d B$ and $t c d A$. These studies from our group [51] and others [70,83,84] highlight a significant role for the mycobiome during CDI, an area that is deserving of further exploration.

Supplementary Materials: The following are available online at http://www.mdpi.com/2309-608X/6/3/100/s1, Figure S1: Quality control of the designed primers. Figure S2: Pre-amplification increases the sensitivity of detection. Figure S3: C. albicans colonization. Figure S4: Relative weight of the mice after receiving olive oil for 6 days. Figure S5: Relative weights of the mice on the days following challenge with C. difficile spores. Figure S6: Histology of the $C$. difficile-infected murine tissues. Figure S7: Cecal microbiota community diversity scores. Figure S8: Vegetative cells and spores after growth in a TY broth for $51 \mathrm{~h}$ with and without oleic acid. Figure S9: Transcription of $t c d B$ normalized to rpoA. Table S1: Primers used. Table S2: Compounds present at higher or lower levels in cecum contents from the C. albicans-colonized mice versus the uncolonized mice. Table S3: Survival of the mice after feeding oils, pilot experiment.

Author Contributions: Conceptualization, C.A.K., J.A.R. and L.M.; investigation, C.A.K., J.A.R. and L.M.; writing-original draft preparation, C.A.K. and J.A.R.; writing-review and editing, C.A.K., J.A.R. and L.M.; supervision, C.A.K.; funding acquisition, C.A.K. All authors have read and agreed to the published version of the manuscript.

Funding: J.A.R. was supported by NIH training grant T32AI007329 and is an IRACDA Scholar (grant K12GM133314). L.M. was supported by R01 AI118898 (to Carol A. Kumamoto). C.A.K. was supported in part by R01 AI118898 (to Carol A. Kumamoto).

Acknowledgments: The authors thank Linc Sonenshein, Aimee Shen, Boris Belitsky and Paola Zucchi for helpful discussion and critical expertise. We also thank Anne Kane for assistance with the analysis of microbiota composition.

Conflicts of Interest: The authors have no conflict of interest to declare. The funders of this research had no role in study design, data collection and interpretation, or the decision to submit the work for publication.

\section{References}

1. Cole, G.T.; Lynn, K.T.; Seshan, K.R.; Pope, L.M. Gastrointestinal and systemic candidosis in immunocompromised mice. J. Med. Vet. Mycol. 1989, 27, 363-380. [CrossRef] [PubMed]

2. Ekenna, O.; Sherertz, R.J. Factors affecting colonization and dissemination of Candida albicans from the gastrointestinal tract of mice. Infect. Immun. 1987, 55, 1558-1563. [CrossRef] [PubMed]

3. Kennedy, M.J. Regulation of Candida albicans populations in the gastrointestinal tract: Mechanisms and significance in GI and systemic candidiasis. Curr Top. Med. Mycol. 1989, 3, 315-402. [PubMed]

4. Kennedy, M.J.; Volz, P.A. Ecology of Candida albicans gut colonization: Inhibition of Candida adhesion, colonization, and dissemination from the gastrointestinal tract by bacterial antagonism. Infect. Immun. 1985, 49, 654-663. [CrossRef] [PubMed]

5. Hopke, A.; Brown, A.J.P.; Hall, R.A.; Wheeler, R.T. Dynamic Fungal Cell Wall Architecture in Stress Adaptation and Immune Evasion. Trends Microbiol. 2018, 26, 284-295. [CrossRef]

6. Iliev, I.D.; Funari, V.A.; Taylor, K.D.; Nguyen, Q.; Reyes, C.N.; Strom, S.P.; Brown, J.; Becker, C.A.; Fleshner, P.R.; Dubinsky, M.; et al. Interactions between commensal fungi and the C-type lectin receptor Dectin-1 influence colitis. Science 2012, 336, 1314-1317. [CrossRef] [PubMed] 
7. Netea, M.G.; Joosten, L.A.; van der Meer, J.W.; Kullberg, B.J.; van de Veerdonk, F.L. Immune defence against Candida fungal infections. Nat. Rev. Immunol. 2015, 15, 630-642. [CrossRef] [PubMed]

8. Plato, A.; Hardison, S.E.; Brown, G.D. Pattern recognition receptors in antifungal immunity. Semin. Immunopathol. 2015, 37, 97-106. [CrossRef]

9. Romani, L.; Zelante, T.; Palmieri, M.; Napolioni, V.; Picciolini, M.; Velardi, A.; Aversa, F.; Puccetti, P. The cross-talk between opportunistic fungi and the mammalian host via microbiota's metabolism. Semin. Immunopathol. 2015, 37, 163-171. [CrossRef]

10. Allison, D.L.; Willems, H.M.; Jayatilake, J.A.; Bruno, V.M.; Peters, B.M.; Shirtliff, M.E. Candida-Bacteria Interactions: Their Impact on Human Disease. Microbiol. Spectr. 2016, 4. [CrossRef]

11. De Sordi, L.; Mühlschlegel, F.A. Quorum sensing and fungal-bacterial interactions in Candida albicans: A communicative network regulating microbial coexistence and virulence. FEMS. Yeast Res. 2009, 9, 990-999. [CrossRef] [PubMed]

12. Jabra-Rizk, M.A.; Meiller, T.F.; James, C.E.; Shirtliff, M.E. Effect of farnesol on Staphylococcus aureus biofilm formation and antimicrobial susceptibility. Antimicrob. Agents Chemother. 2006, 50, 1463-1469. [CrossRef] [PubMed]

13. Hogan, D.A.; Kolter, R. Pseudomonas-Candida interactions: An ecological role for virulence factors. Science 2002, 296, 2229-2232. [CrossRef]

14. Hogan, D.A.; Vik, A.; Kolter, R. A Pseudomonas aeruginosa quorum-sensing molecule influences Candida albicans morphology. Mol. Microbiol. 2004, 54, 1212-1223. [CrossRef] [PubMed]

15. Morales, D.K.; Hogan, D.A. Candida albicans interactions with bacteria in the context of human health and disease. PLOS Pathog. 2010, 6, e1000886. [CrossRef]

16. Erb Downward, J.R.; Falkowski, N.R.; Mason, K.L.; Muraglia, R.; Huffnagle, G.B. Modulation of Post-Antibiotic Bacterial Community Reassembly and Host Response by Candida albicans. Sci. Rep. 2013, 3, 2191. [CrossRef]

17. Bartlett, J.G. Management of Clostridium difficile infection and other antibiotic-associated diarrhoeas. Eur J. Gastroenterol. Hepatol. 1996, 8, 1054-1061. [CrossRef] [PubMed]

18. Kelly, C.P.; LaMont, J.T. Clostridium difficile infection. Annu Rev. Med. 1998, 49, 375-390. [CrossRef]

19. McCollum, D.L.; Rodriguez, J.M. Detection, treatment, and prevention of Clostridium difficile infection. Clin. Gastroenterol. Hepatol. 2012, 10, 581-592. [CrossRef]

20. Bartlett, J.G. Antibiotic-associated colitis. Dis Mon. 1984, 30, 1-54.

21. Bartlett, J.G. Treatment of antibiotic-associated pseudomembranous colitis. Rev. Infect. Dis 1984, 6, S235-S241. [CrossRef] [PubMed]

22. Bartlett, J.G. Antibiotic-associated pseudomembranous colitis. Rev. Infect. Dis. 1979, 16, 530-539. [CrossRef]

23. Theriot, C.M.; Bowman, A.A.; Young, V.B. Antibiotic-Induced Alterations of the Gut Microbiota Alter Secondary Bile Acid Production and Allow for Clostridium difficile Spore Germination and Outgrowth in the Large Intestine. mSphere 2016, 1, e00045-15. [CrossRef]

24. Dicks, L.M.T.; Mikkelsen, L.S.; Brandsborg, E.; Marcotte, H. Clostridium difficile, the Difficult "Kloster" Fuelled by Antibiotics. Curr. Microbiol. 2018, 76, 774-782. [CrossRef]

25. Lessa, F.C.; Mu, Y.; Bamberg, W.M.; Beldavs, Z.G.; Dumyati, G.K.; Dunn, J.R.; Farley, M.M.; Holzbauer, S.M.; Meek, J.I.; Phipps, E.C.; et al. Burden of Clostridium difficile Infection in the United States. N. Engl. J. Med. 2015, 372, 825-834. [CrossRef]

26. Gerding, D.N.; Lessa, F.C. The epidemiology of Clostridium difficile infection inside and outside health care institutions. Infect. Dis. Clin. North. Am. 2015, 29, 37-50. [CrossRef]

27. Dubberke, E.R.; Olsen, M.A. Burden of Clostridium difficile on the healthcare system. Clin. Infect. Dis. 2012, 55, S88-S92. [CrossRef]

28. Sebaihia, M.; Wren, B.W.; Mullany, P.; Fairweather, N.F.; Minton, N.; Stabler, R.; Thomson, N.R.; Roberts, A.P.; Cerdeno-Tarraga, A.M.; Wang, H.; et al. The multidrug-resistant human pathogen Clostridium difficile has a highly mobile, mosaic genome. Nat. Genet. 2006, 38, 779-786. [CrossRef]

29. Tenover, F.C.; Tickler, I.A.; Persing, D.H. Antimicrobial-resistant strains of Clostridium difficile from North America. Antimicrob. Agents Chemother. 2012, 56, 2929-2932. [CrossRef]

30. He, M.; Miyajima, F.; Roberts, P.; Ellison, L.; Pickard, D.J.; Martin, M.J.; Connor, T.R.; Harris, S.R.; Fairley, D.; Bamford, K.B.; et al. Emergence and global spread of epidemic healthcare-associated Clostridium difficile. Nat. Genet. 2013, 45, 109-113. [CrossRef] 
31. Abou Chakra, C.N.; Pepin, J.; Sirard, S.; Valiquette, L. Risk factors for recurrence, complications and mortality in Clostridium difficile infection: A systematic review. PLoS ONE 2014, 9, e98400. [CrossRef] [PubMed]

32. Alfa, M.; Harding, G.; Ronald, A.; Light, R.; Macfarlane, N.; Olson, N.; Degagne, P.; Kasdorf, K.; Simor, A.; Macdonald, K.; et al. Diarrhea recurrence in patients with Clostridium difficile-associated diarrhea: Role of concurrent antibiotics. Can. J. Infect. Dis. 1999, 10, 287-294. [CrossRef] [PubMed]

33. Choi, H.K.; Kim, K.H.; Lee, S.H.; Lee, S.J. Risk factors for recurrence of Clostridium difficile infection: Effect of vancomycin-resistant enterococci colonization. J. Korean Med. Sci. 2011, 26, 859-864. [CrossRef] [PubMed]

34. Lupse, M.; Flonta, M.; Cioara, A.; Filipescu, I.; Todor, N. Predictors of first recurrence in Clostridium difficileassociated disease. A study of 306 patients hospitalized in a Romanian tertiary referral center. J. Gastrointestin Liver Dis. 2013, 22, 397-403. [PubMed]

35. Petrella, L.A.; Sambol, S.P.; Cheknis, A.; Nagaro, K.; Kean, Y.; Sears, P.S.; Babakhani, F.; Johnson, S.; Gerding, D.N. Decreased Cure and Increased Recurrence Rates for Clostridium difficile Infection Caused by the Epidemic C. difficile BI Strain. Clin. Infect. Dis. 2012, 55, 351-357. [CrossRef] [PubMed]

36. Wilcox, M.H.; Fawley, W.N.; Settle, C.D.; Davidson, A. Recurrence of symptoms in Clostridium difficile infection-relapse or reinfection? J. Hosp. Infect. 1998, 38, 93-100. [CrossRef]

37. Kuehne, S.A.; Cartman, S.T.; Heap, J.T.; Kelly, M.L.; Cockayne, A.; Minton, N.P. The role of toxin A and toxin B in Clostridium difficile infection. Nature 2010, 467, 711-713. [CrossRef]

38. Voth, D.E.; Ballard, J.D. Clostridium difficile toxins: Mechanism of action and role in disease. Clin. Microbiol. Rev. 2005, 18, 247-263. [CrossRef]

39. Sorg, J.A.; Sonenshein, A.L. Bile salts and glycine as cogerminants for Clostridium difficile spores. J. Bacteriol. 2008, 190, 2505-2512. [CrossRef]

40. Wilson, K.H.; Kennedy, M.J.; Fekety, F.R. Use of sodium taurocholate to enhance spore recovery on a medium selective for Clostridium difficile. J. Clin. Microbiol. 1982, 15, 443-446. [CrossRef]

41. Ridlon, J.M.; Kang, D.J.; Hylemon, P.B. Bile salt biotransformations by human intestinal bacteria. J. Lipid Res. 2006, 47, 241-259. [CrossRef] [PubMed]

42. Theriot, C.M.; Koenigsknecht, M.J.; Carlson, P.E., Jr.; Hatton, G.E.; Nelson, A.M.; Li, B.; Huffnagle, G.B.; Li, J.Z.; Young, V.B. Antibiotic-induced shifts in the mouse gut microbiome and metabolome increase susceptibility to Clostridium difficile infection. Nat. Commun. 2014, 5, 3114. [CrossRef] [PubMed]

43. Buffie, C.G.; Bucci, V.; Stein, R.R.; McKenney, P.T.; Ling, L.; Gobourne, A.; No, D.; Liu, H.; Kinnebrew, M.; Viale, A.; et al. Precision microbiome reconstitution restores bile acid mediated resistance to Clostridium difficile. Nature 2015, 517, 205-208. [CrossRef] [PubMed]

44. Sorg, J.A.; Sonenshein, A.L. Inhibiting the initiation of Clostridium difficile spore germination using analogs of chenodeoxycholic acid, a bile acid. J. Bacteriol. 2010, 192, 4983-4990. [CrossRef] [PubMed]

45. Hryckowian, A.J.; Van Treuren, W.; Smits, S.A.; Davis, N.M.; Gardner, J.O.; Bouley, D.M.; Sonnenburg, J.L. Microbiota-accessible carbohydrates suppress Clostridium difficile infection in a murine model. Nat. Microbiol. 2018, 3, 662-669. [CrossRef] [PubMed]

46. Manian, F.A.; Bryant, A. Does Candida Species Overgrowth Protect Against Clostridium difficile Infection? Clin. Infect. Dis. 2013, 56, 464-465. [CrossRef]

47. Shiuan Hsu, M.; Tay Wang, J.; Kuei Huang, W.; Ching Liu, Y.; Chwen Chang, S. Prevalence and clinical features of Clostridium difficile-associated diarrhea in a tertiary hospital in northern Taiwan. J. Microbiol. Immunol. Infect. 2006, 39, 242-248.

48. Raponi, G.; Visconti, V.; Brunetti, G.; Ghezzi, M.C. Clostridium difficile infection and Candida colonization of the gut: Is there a correlation? Clin. Infect. Dis. 2014, 59, 1648-1649. [CrossRef]

49. Nerandzic, M.M.; Mullane, K.; Miller, M.A.; Babakhani, F.; Donskey, C.J. Reduced Acquisition and Overgrowth of Vancomycin-Resistant Enterococci and Candida Species in Patients Treated With Fidaxomicin Versus Vancomycin for Clostridium difficile Infection. Clin. Infect. Dis. 2012, 55, S121-S126. [CrossRef] [PubMed]

50. Zuo, T.; Wong, S.H.; Cheung, C.P.; Lam, K.; Lui, R.; Cheung, K.; Zhang, F.; Tang, W.; Ching, J.Y.L.; $\mathrm{Wu}$, J.C.Y.; et al. Gut fungal dysbiosis correlates with reduced efficacy of fecal microbiota transplantation in Clostridium difficile infection. Nat. Commun. 2018, 9, 3663. [CrossRef]

51. Markey, L.; Shaban, L.; Green, E.R.; Lemon, K.P.; Mecsas, J.; Kumamoto, C.A. Pre-colonization with the commensal fungus Candida albicans reduces murine susceptibility to Clostridium difficile infection. Gut Microbes 2018, 9, 497-509. [CrossRef] 
52. Brown, D.H., Jr.; Giusani, A.D.; Chen, X.; Kumamoto, C.A. Filamentous growth of Candida albicans in response to physical environmental cues and its regulation by the unique CZF1 gene. Mol. Microbiol. 1999, 34, 651-662. [CrossRef]

53. Sherman, F. Getting started with yeast. Methods Enzym. 1991, 194, 3-21. [CrossRef]

54. Sorg, J.A.; Dineen, S.S. Laboratory maintenance of Clostridium difficile. Curr. Protoc. Microbiol. 2009, Chapter 9, Unit9A 1. [CrossRef]

55. Maniar, A.C.; Williams, T.W.; Hammond, G.W. Detection of Clostridium difficile toxin in various tissue culture monolayers. J. Clin. Microbiol. 1987, 25, 1999-2000. [CrossRef] [PubMed]

56. Chong, J.; Wishart, D.S.; Xia, J. Using MetaboAnalyst 4.0 for Comprehensive and Integrative Metabolomics Data Analysis. Curr. Protoc. Bioinform. 2019, 68, e86. [CrossRef] [PubMed]

57. Xia, J.; Psychogios, N.; Young, N.; Wishart, D.S. MetaboAnalyst: A web server for metabolomic data analysis and interpretation. Nucleic Acids Res. 2009, 37, W652-W660. [CrossRef] [PubMed]

58. Caporaso, J.G.; Lauber, C.L.; Walters, W.A.; Berg-Lyons, D.; Huntley, J.; Fierer, N.; Owens, S.M.; Betley, J.; Fraser, L.; Bauer, M.; et al. Ultra-high-throughput microbial community analysis on the Illumina HiSeq and MiSeq platforms. ISME J. 2012, 6, 1621-1624. [CrossRef] [PubMed]

59. Bolyen, E.; Rideout, J.R.; Dillon, M.R.; Bokulich, N.A.; Abnet, C.C.; Al-Ghalith, G.A.; Alexander, H.; Alm, E.J.; Arumugam, M.; Asnicar, F.; et al. Reproducible, interactive, scalable and extensible microbiome data science using QIIME 2. Nat. Biotechnol. 2019, 37, 852-857. [CrossRef] [PubMed]

60. Callahan, B.J.; McMurdie, P.J.; Rosen, M.J.; Han, A.W.; Johnson, A.J.; Holmes, S.P. DADA2: High-resolution sample inference from Illumina amplicon data. Nat. Methods 2016, 13, 581-583. [CrossRef] [PubMed]

61. Katoh, K.; Misawa, K.; Kuma, K.; Miyata, T. MAFFT: A novel method for rapid multiple sequence alignment based on fast Fourier transform. Nucleic Acids Res. 2002, 30, 3059-3066. [CrossRef] [PubMed]

62. Price, M.N.; Dehal, P.S.; Arkin, A.P. FastTree 2-approximately maximum-likelihood trees for large alignments. PLoS ONE 2010, 5, e9490. [CrossRef] [PubMed]

63. Lozupone, C.A.; Hamady, M.; Kelley, S.T.; Knight, R. Quantitative and qualitative beta diversity measures lead to different insights into factors that structure microbial communities. Appl. Env. Microbiol. 2007, 73, 1576-1585. [CrossRef] [PubMed]

64. McDonald, D.; Price, M.N.; Goodrich, J.; Nawrocki, E.P.; DeSantis, T.Z.; Probst, A.; Andersen, G.L.; Knight, R.; Hugenholtz, P. An improved Greengenes taxonomy with explicit ranks for ecological and evolutionary analyses of bacteria and archaea. ISME J. 2012, 6, 610-618. [CrossRef]

65. Bouillaut, L.; McBride, S.M.; Sorg, J.A. Genetic manipulation of Clostridium difficile. Curr. Protoc. Microbiol. 2011, Chapter 9, Unit 9A 2. [CrossRef]

66. Husson, M.O.; Ley, D.; Portal, C.; Gottrand, M.; Hueso, T.; Desseyn, J.L.; Gottrand, F. Modulation of host defence against bacterial and viral infections by omega-3 polyunsaturated fatty acids. J. Infect. 2016, 73, 523-535. [CrossRef]

67. Panpetch, W.; Somboonna, N.; Palasuk, M.; Hiengrach, P.; Finkelman, M.; Tumwasorn, S.; Leelahavanichkul, A. Oral Candida administration in a Clostridium difficile mouse model worsens disease severity but is attenuated by Bifidobacterium. PLoS ONE 2019, 14, e0210798. [CrossRef] [PubMed]

68. Samonis, G.; Gikas, A.; Anaissie, E.J.; Vrenzos, G.; Maraki, S.; Tselentis, Y.; Bodey, G.P. Prospective evaluation of effects of broad-spectrum antibiotics on gastrointestinal yeast colonization of humans. Antimicrob. Agents Chemother. 1993, 37, 51-53. [CrossRef] [PubMed]

69. Clark, J.D. Influence of antibiotics or certain intestinal bacteria on orally administered Candida albicans in germ-free and conventional mice. Infect. Immun. 1971, 4, 731-737. [CrossRef] [PubMed]

70. Stewart, D.; Romo, J.A.; Lamendella, R.; Kumamoto, C.A. The role of fungi in C. difficile infection: An underappreciated transkingdom interaction. Fungal Genet. Biol. 2019, 129, 1-6. [CrossRef]

71. Agoramoorthy, G.; Chandrasekaran, M.; Venkatesalu, V.; Hsu, M.J. Antibacterial and antifungal activities of fatty acid methyl esters of the blind-your-eye mangrove from India. Braz. J. Microbiol. 2007, 38, 739-742. [CrossRef]

72. Desbois, A.P.; Lawlor, K.C. Antibacterial activity of long-chain polyunsaturated fatty acids against Propionibacterium acnes and Staphylococcus aureus. Mar. Drugs 2013, 11, 4544-4557. [CrossRef] [PubMed]

73. Muthamil, S.; Prasath, K.G.; Priya, A.; Precilla, P.; Pandian, S.K. Global proteomic analysis deciphers the mechanism of action of plant derived oleic acid against Candida albicans virulence and biofilm formation. Sci. Rep. 2020, 10, 5113. [CrossRef] [PubMed] 
74. Carabajal, M.A.; Viarengo, G.; Yim, L.; Martínez-Sanguiné, A.; Mariscotti, J.F.; Chabalgoity, J.A.; Rasia, R.M.; Véscovi, E.G. PhoQ is an unsaturated fatty acid receptor that fine-tunes Salmonella pathogenic traits. Sci. Signal. 2020, 13, eaaz3334. [CrossRef] [PubMed]

75. Fletcher, J.R.; Erwin, S.; Lanzas, C.; Theriot, C.M. Shifts in the Gut Metabolome and Clostridium difficile Transcriptome throughout Colonization and Infection in a Mouse Model. mSphere 2018, 3. [CrossRef] [PubMed]

76. Mefferd, C.C.; Bhute, S.S.; Phan, J.R.; Villarama, J.V.; Do, D.M.; Alarcia, S.; Abel-Santos, E.; Hedlund, B.P. A High-Fat/High-Protein, Atkins-Type Diet Exacerbates Clostridioides (Clostridium) difficile Infection in Mice, whereas a High-Carbohydrate Diet Protects. mSystems 2020, 5. [CrossRef]

77. Blankenship-Paris, T.L.; Walton, B.J.; Hayes, Y.O.; Chang, J. Clostridium difficile infection in hamsters fed an atherogenic diet. Vet. Pathol. 1995, 32, 269-273. [CrossRef]

78. Lee, T.R.; Hsu, H.P.; Shaw, G.C. Transcriptional regulation of the Bacillus subtilis bscR-CYP102A3 operon by the BscR repressor and differential induction of cytochrome CYP102A3 expression by oleic acid and palmitate. J. Biochem. 2001, 130, 569-574. [CrossRef]

79. Deakin, L.J.; Clare, S.; Fagan, R.P.; Dawson, L.F.; Pickard, D.J.; West, M.R.; Wren, B.W.; Fairweather, N.F.; Dougan, G.; Lawley, T.D. The Clostridium difficile spo0A gene is a persistence and transmission factor. Infect. Immun. 2012, 80, 2704-2711. [CrossRef]

80. Underwood, S.; Guan, S.; Vijayasubhash, V.; Baines, S.D.; Graham, L.; Lewis, R.J.; Wilcox, M.H.; Stephenson, K. Characterization of the sporulation initiation pathway of Clostridium difficile and its role in toxin production. J. Bacteriol. 2009, 191, 7296-7305. [CrossRef]

81. Childress, K.O.; Edwards, A.N.; Nawrocki, K.L.; Anderson, S.E.; Woods, E.C.; McBride, S.M. The Phosphotransfer Protein CD1492 Represses Sporulation Initiation in Clostridium difficile. Infect. Immun. 2016, 84, 3434-3444. [CrossRef] [PubMed]

82. Strauch, M.A.; Trach, K.A.; Day, J.; Hoch, J.A. Spo0A activates and represses its own synthesis by binding at its dual promoters. Biochimie 1992, 74, 619-626. [CrossRef]

83. Lamendella, R.; Wright, J.R.; Hackman, J.; McLimans, C.; Toole, D.R.; Bernard Rubio, W.; Drucker, R.; Wong, H.T.; Sabey, K.; Hegarty, J.P.; et al. Antibiotic Treatments for Clostridium difficile Infection Are Associated with Distinct Bacterial and Fungal Community Structures. mSphere 2018, 3, e00572-17. [CrossRef] [PubMed]

84. Sangster, W.; Hegarty, J.P.; Schieffer, K.M.; Wright, J.R.; Hackman, J.; Toole, D.R.; Lamendella, R.; Stewart, D.B. Bacterial and Fungal Microbiota Changes Distinguish C. difficile Infection from Other Forms of Diarrhea: Results of a Prospective Inpatient Study. Front. Microbiol. 2016, 7. [CrossRef] [PubMed] 